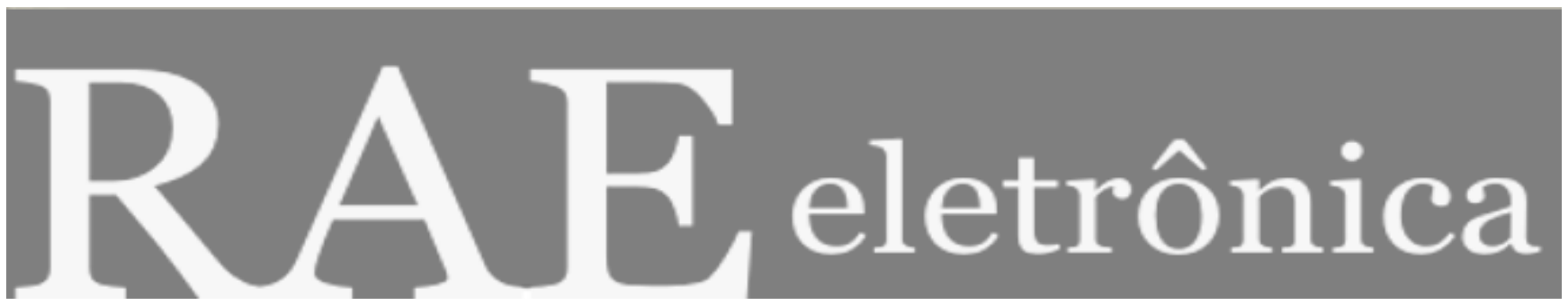

\title{
ERGUENDO-SE PELOS PRÓPRIOS CABELOS: AUTO-EMPREGO E REESTRUTURAÇÃO PRODUTIVA NO BRASIL
}

Por:

\section{Rosa Maria Vieira}

RAE-eletrônica, v. 2, n. 2, jul-dez/2003.

http://www.rae.com.br/eletronica/index.cfm?FuseAction=Artigo\&ID=1907\&Secao=RESENHAS\&Vol ume $=2 \&$ Numero $=2 \&$ Ano $=2003$

CCopyright, 2002, RAE-eletrônica. Todos os direitos, inclusive de tradução, são reservados. É permitido citar parte de artigos sem autorização prévia desde que seja identificada a fonte. A reprodução total de artigos é proibida. Os artigos só devem ser usados para uso pessoal e nãocomercial. Em caso de dúvidas, consulte a redação: redacao@rae.com.br.

A RAE-eletrônica é a revista on-line da FGV-EAESP, totalmente aberta e criada com o objetivo de agilizar a veiculação de trabalhos inéditos. Lançada em janeiro de 2002, com perfil acadêmico, é dedicada a professores, pesquisadores e estudantes. Para mais informações consulte o site www.rae.com.br/eletronica.

RAE-eletrônica

ISSN 1676-5648

(C)2002 Editora: Fundação Getulio Vargas - Escola de Administração de Empresas de São Paulo.
F U N D A Ç Ã 0 GETULIO VARGAS

Escola de Administração de Empresas de São Paulo 
Por

\section{Rosa Maria Vieira}

Professora do Departamento de Fundamentos Sociais e Jurídicos da FGV-EAESP.

E-mail: romavieira@uol.com.br

\section{Erguendo-se Pelos Próprios Cabelos: Auto-Emprego e Reestruturação Produtiva no Brasil. De João Batista Pamplona.}

São Paulo: Germinal/ FAPESP, 2001, 366 p.

Analisando o significado do academicismo para produção intelectual norte-americana, no $2^{\circ}$ pós-guerra, Russel Jacoby aponta alguns problemas da criação teórica confinada aos muros das universidades. Desdenhando o universo público e desenvolvendo um conhecimento crescentemente especializado, os intelectuais acadêmicos mudaram sua linguagem e afastaram-se dos temas essenciais da esfera pública. Uma nova audiência modelou o hermetismo destes intelectuais - seus pares na academia - e as preocupações restritas ao mundo universitário substituíram as amplas questões de interesse geral. Dependentes de financiamentos e embaraçados pela burocracia, abriram mão da independência e da carga ética que caracterizavam a intelligentsia comprometida com a cultura pública. (SADER, Emir. O Poder, Cadê o Poder. São Paulo: Boitempo, 1997, pp. 95-97)

Obviamente, o Brasil não escapou a esta tendência. À geração de intelectuais, que construiu interpretações clássicas do Brasil, no bojo do debate das grandes questões nacionais, sucederam-se, uma após outra, linhagens de cientistas sociais especializados, acadêmicos restritos aos campi universitários e sintonizados com os modismos teóricos dos países centrais. Se há exceções significativas na universidade brasileira, e elas são inúmeras, a regra, no entanto, é a produção intelectual hermética, inacessível ao público geral, e o tratamento de questões que, quando muito, apenas tangenciam os temas essenciais da "esfera pública".

Este não é, certamente, o caso do livro de João Batista Pamplona. Resultado de uma tese de doutorado, este trabalho, em que pese sua origem e formatação acadêmicas, trata com rigor e linguagem clara um dos mais candentes problemas do mundo contemporâneo, que no Brasil se manifesta de modo particularmente perverso: os efeitos da crise e do reordenamento da acumulação capitalista sobre o trabalho, focados aqui sob o ângulo do auto- emprego.

Fiel aos princípios dos paradigmas acadêmicos, Pamplona passou em revista a literatura disponível sobre esta questão, visitou as diversas correntes teóricas que trataram desta problemática e, sob a ótica da Escola da Regulação, analisou as profundas alterações no mercado de trabalho, a partir da década de 70 .

Não se deve entender, porém, que a fidelidade aos cânones acadêmicos tenha afastado o autor do trato das questões polêmicas que envolvem o chamado "setor informal urbano", ou o autoemprego. Isto fica evidente quando elege, como eixo central do seu livro, uma questão que está muito longe de um tratamento consensual: o auto-emprego urbano é uma alternativa promissora, ou apenas uma manifestação da precarização do trabalho? 
Nos primeiros capítulos, o autor dedica-se à crise do fordismo e ao processo de reestruturação capitalista, a partir de um balanço das principais linhas de interpretação teórica, para chegar à "análise da crise do assalariamento", da deterioração do mercado de trabalho, da precarização do emprego, a partir dos anos 80 . Tudo isto tendo em vista a análise do auto-emprego e do setor informal no Brasil, cuja pesquisa, diga-se de passagem, põe em relevo o rigor e a qualidade deste estudo.

No exame da problemática nacional, delimitado seu universo de análise - a Região Metropolitana de São Paulo, nos anos 90 -, Pamplona recorre a dados primários obtidos pelo IBGE, em 1997, e, sobretudo, aos resultados da Pesquisa de Emprego e Desemprego do SEADE, com a intenção de detectar tendências e qualificar a precarização da força de trabalho urbana autoempregada.

Segundo Pamplona, o auto-emprego é a situação em que o trabalhador controla seu processo de trabalho, os meios de produção e participa diretamente da atividade produtiva. Sem renda definida, seu objetivo é prover o próprio emprego e a subsistência e não valorizar o capital. Frente ao amplo continuum de situações englobadas nesta categoria, o autor refere-se aos trabalhadores autônomos (os de "conta própria"), aos pequenos empregadores e aos membros de cooperativas de produtores.

Até a década de 70, no centro da prosperidade do capitalismo hegemônico estava a "relação salarial fordista" - assalariamento, emprego permanente em grandes empresas, período integral, contratos coletivos, regulação por legislação trabalhista e sistema de proteção social. Neste quadro, a proporção de auto-empregados urbanos encontrava-se em declínio. A interrupção da prosperidade fordista, no entanto, pôs em movimento uma profunda reestruturação econômica e tecnológica, de que são exemplos a microeletrônica, a flexibilidade produtiva, a diminuição da incorporação de trabalhadores não-qualificados e a globalização financeirizada. Isto abalou profundamente o mundo do trabalho, trazendo desemprego de longa duração, empregos informais e em setores de pouca produtividade, baixos salários, trabalho em tempo parcial, crescimento da subcontratação e da terceirização de trabalhadores, enfraquecimento dos sindicatos. Em suma, a precarização do trabalho e a vulnerabilidade social. Em tal cenário, a tendência anterior se inverteu, dando lugar ao auto-emprego urbano.

Pamplona reconhece a heterogeneidade do auto-emprego e, por isto, destaca não apenas as causas que "empurram" os trabalhadores para a informalidade, mas também as que os "atraem", pois se para alguns esta é a única saída possível, para outros (não muitos, é importante frisar), ela é a melhor alternativa. Neste caso, a explicação estaria nas inovações tecnológicas e na expansão da demanda por produtos e serviços diferenciados.

Nos países, centrais, as desvantagens do auto-emprego atingem, sobretudo, os trabalhadores mais frágeis - mulheres, jovens e os pouco qualificados. Para estes, o auto-emprego é uma forma de obter alguma renda e manter a auto-estima, cumprindo a função paliativa de "absorção de choques", ao impedir situações sociais mais perversas. Outra, porém, é a face do auto-emprego para aqueles, mais privilegiados (e, sem dúvida, uma minoria), que dispõem de recursos e boa inserção social - homens maduros, com mais capital e maior qualificação. Neste caso, auto-emprego pode significar sucesso e altos rendimentos. 


\section{Mas, e a precarização do trabalho no Brasil?}

Partindo do pressuposto que a particularidade das áreas subdesenvolvidas impede que o auto-emprego possa ter o mesmo tratamento teórico dos países centrais, Pamplona afirma que, na periferia, é no modo de organização da unidade de produção que se deve buscar a definição do que é o informal: trabalho em unidades de produção não-capitalistas no interior do capitalismo trabalhadores domésticos, os conta própria, proprietários de pequenos negócios e seus empregados. Nestes casos, o objetivo não seria a acumulação de capital, mas a criação de emprego e renda, confundindo-se o auto-emprego com a informalidade.

No Brasil, a informalidade e o auto-emprego ganharam novas dimensões na era FHC, com a abertura econômica, o enxugamento do Estado e o baixo crescimento econômico. Aqui, as mudanças na estrutura produtiva não foram simplesmente ajustes superficiais, temporários. Ocorreram profundas alterações que, combinando perversamente a tendência à reestruturação pósfordista com os problemas seculares de subemprego e desemprego, ocasionaram uma deterioração sem precedentes do mercado de trabalho. Cresceu o desemprego aberto e de longa duração, ampliaram-se as ocupações precárias e caiu sensivelmente a qualidade do emprego, pois os setores que ofereciam os melhores postos de trabalho passaram a empregar menos .

Segundo Pamplona, na última década (89/99), a ocupação industrial na RMSP caiu 30\%, enquanto que nos serviços domésticos cresceu 65\% e na prestação de serviços 39\%. Assim, é possível notar que, simultaneamente à diminuição do emprego industrial, observou-se uma expansão compensatória do setor de serviços, que, como se sabe, sob o rótulo genérico abriga formidáveis diferenças - dos serviços mais qualificados e melhor remunerados, aos menos qualificados e pior remunerados, onde predominam "estratégias de sobrevivência". Em suma, um crescimento polarizado do setor de serviços que permitiu a expansão de um "pólo superior", resultado da reestruturação industrial, e por outro, estimulou um "pólo inferior", motivado pelo baixo crescimento econômico.

São estas as análises que permitem a Pamplona a conclusão de que, quando se trata do autoemprego em São Paulo, a realidade comporta extremos. Numa de suas pontas, a precarização do trabalho, representada pelos "empregados de auto-empregado" e trabalhadores informais, altamente vulneráveis - mulheres por conta própria, auto-empregados nos "serviços de reparação, pessoais, domiciliares e de diversões" e auto-empregados na "construção civil". E, numa outra, os autoempregados empregadores e auto-empregados nos "serviços técnicos e auxiliares", cuja expansão pode indicar situações promissoras de trabalho.

Enfim, o mercado de trabalho brasileiro revela-se, hoje, polarizado e não simplesmente precarizado. Ou, melhor, o auto-emprego, que nem sempre, mas quase sempre, é "o lugar dos pobres urbanos", contribuiu, fortemente, para a segmentação do mundo do trabalho e o crescente processo de polarização social em nosso país. 